\title{
REAL TIME WEB BASED SYSTEM FOR OBSERVING SAG AT SUBSTATION
}

\author{
Sangeeta Kamboj ${ }^{1}$ and Dr. Ratna Dahiya ${ }^{2}$ \\ ${ }^{1}$ Research Scholar, National Institute of Technology Kurukshetra - 136119, Haryana, \\ India \\ http://www.nitkkr.ac.in/ \\ ${ }^{2}$ Faculty, National Institute of Technology Kurukshetra- 136119, Haryana, India \\ http://www.nitkkr.ac.in/
}

\begin{abstract}
The paper describes the designing of web based system for transmission of GPS measurements so that power system operator may monitor overhead conductor sag of power transmission line at substation in real time. The testing results of transmission of GPS measurements from $11 \mathrm{KV}$ power transmission line to substation have also been discussed in detail. Raw GPS measurements are not so accurate that these are usable for overhead conductor sag evaluation. The estimated GPS altitude measurements obtained using signal processing techniques such as Least Square Parameter Estimation(LSPE) and Haar Wavelet Transform (HWT) with LSPE are also presented in this paper.
\end{abstract}

\section{KEYWORDS}

GPS, LSPE method, Wavelet Analysis, Web Server, Overhead conductor sag, NMEA0183.

\section{INTRODUCTION}

GPS is satellite based radio positioning and navigation system. It provides position in three dimension and time information to users worldwide with twenty four hours a day [2]. It was declared operational for civilian users in December 1993. The developments in applications of GPS over last 10 years have done at higher rate than advancements in realization of GPS constellation. It is maintained by the United States government and every user can freely access this with a GPS receiver. According to W. Wooden, the detailed definition of GPS is "The Navstar GPS is an all-weather, space based navigation system under development by the Department of Defense to satisfy the requirements for the military forces to accurately determine their position, velocity, and time in common reference system, anywhere on or near earth on a continuous basis". A GPS receiver calculates its position by precisely timing the signals sent by GPS satellites. There may be visible more than four satellites but only four satellites are used in position calculation of GPS receiver [3,9].The application market for vehicular tracking and DOI : $10.5121 /$ ijcsea.2012.2106 
monitoring, digital video processing, recording and transmission is nowadays considered one of the most promising in the security area [8]. Tracking systems were first developed for the shipping industry because they wanted to determine where each vehicle was at any given time. But nowadays Automatic Vehicle Location system has been used which transmit the vehicle location information in real time. Real time vehicular tracking system incorporates a hardware device installed in the vehicle and a remote Tracking server [7]. The ability of GPS Technology to provide time synchronization in order of nanoseconds over wide area has opened up the usage of GPS in electric power systems for its reliable and secure operation $[5,6]$.

The most concerned issue about GPS application in measurement of overhead conductor sag is its accuracy. There are several factors that affect the accuracy of GPS [4]. Various signal processing techniques such as LSPE method and HWT with LSPE to improve accuracy of GPS measurements are used in the paper. In the paper test system for GPS data transmission to Web Server at 66KV Grid Substation Idgah, sector6, Faridabad has been designed. The testing results of GPS data transmission from pole of overhead conductor of 11KV Public Health Feeder, sector 6, Faridabad to substation for sag measurement are also shown in the paper.

\section{WEB BASED SYSTEM DESIGN AND IMPLEMENTATION}

The overhead conductor position is determined using GPS and transmission mechanism could be a satellite, terrestrial radio or cellular connection from overhead conductor to a radio receiver, satellite or nearby cell tower of power substation. The main aim of the transmission of GPS data from overhead conductor to remotely located server is as follows:

- Exploring GPS based sag observation at substation for monitoring purposes.

- Designing System for GPS data transmission through TCP/IP with following features.

- Acquisition of overhead conductor's position in terms of latitude, longitude and altitude after specified interval of time at control room of substation.

- Transmission of GPS data provided by GPS receiver to be placed on overhead conductor to Web Server so that authorized users can access the GPS data via website over the internet.

Overall Web Based System is partitioned into two major design units:

1. On-Overhead Conductor Unit

2. Remote Server/Control Room of Substation

\section{On-Overhead Conductor Unit}

This is major part of the system. It is responsible for acquiring the current position of overhead conductor (latitude, longitude and altitude). This unit is also responsible for transmitting the current position of overhead conductor to Web Server located anywhere in the world. The current position of overhead conductor provided by GPS receiver needs to be processed using any GPS logging software. Thus current position of overhead conductor provided by GPS receiver is transferred to NMEA/GPS logger software through serial interface via Bluetooth link. GPS receiver can also provide other information such as time of GPS fix, status of GPS fix and 
number of satellites used to compute current location information. GPS fix means last reported location. For sag measuring purposes only altitude of overhead conductor is required.

When all required information is extracted and processed, it needs to be transmitted to remote server which will be able to display this information to end user. For real time observation of overhead conductor sag of power transmission lines, reliable data transmission to remote server is very important. Wireless network is required for transmission of logged file to remote server. Existing TCP/IP network is selected to transmit the logged file to remote server because of broad coverage of this network. For transmission of logged file over internet through TCP/IP Modem is used. The logged file is synchronized with FTP Server.

The figure 1 shows basic block diagram of On-Overhead Conductor Unit.

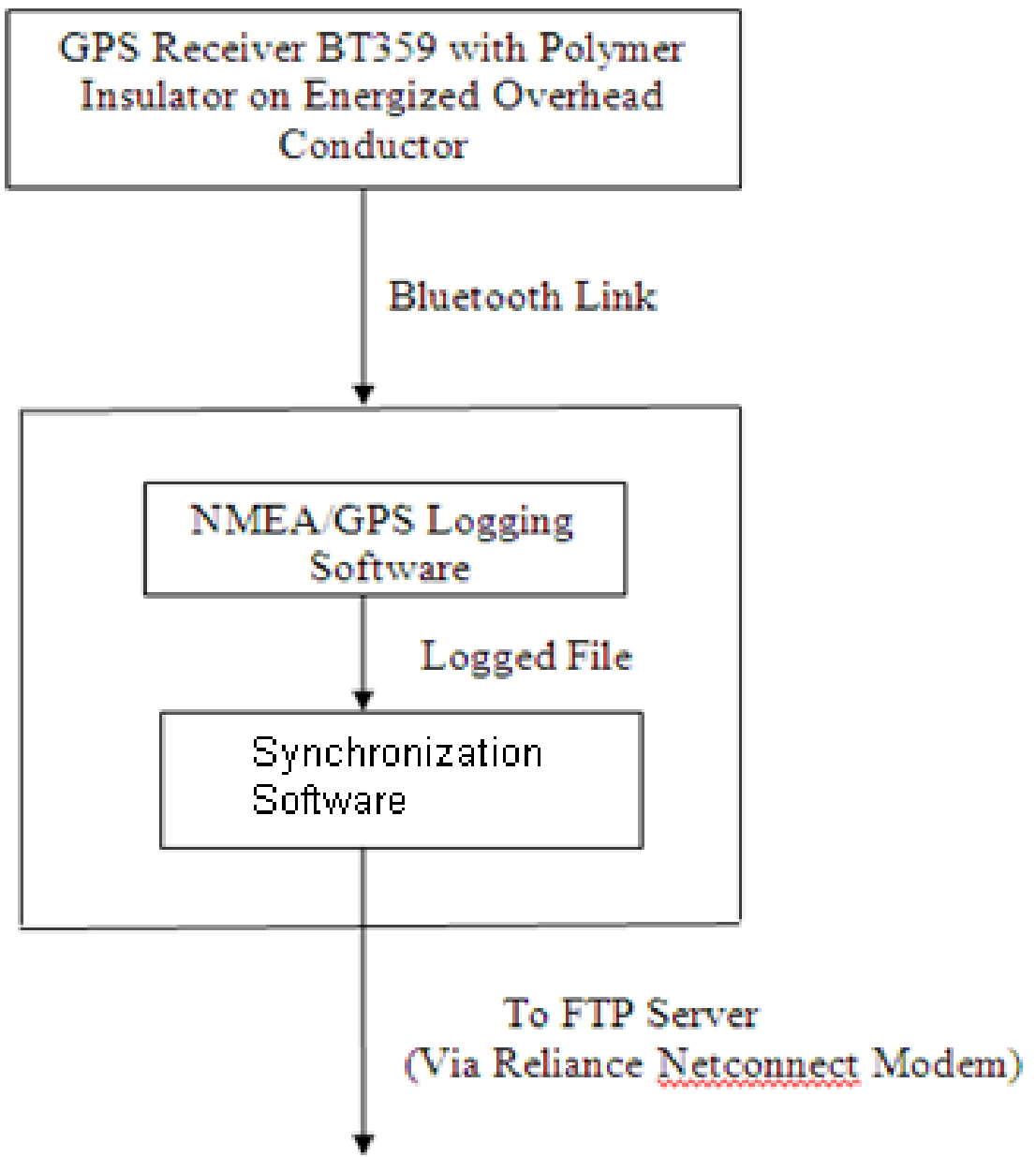

Figure 1. Block Diagram of On-Overhead Conductor Unit 


\section{Remote Server/Control Room of Substation}

In this case remote server is at control room of 66KV Grid Substation Idgah, sector6, Faridabad, Haryana, India. At this substation GPS data has been received for observation of overhead conductor sag of $11 \mathrm{KV}$ Public health feeder. To receive logged file from FTP Server, Modem at laptop of substation is used. Remote Server has a Reliance Netconnect Modem attached to laptop that receive logged file from FTP server (as transmission of logged file to FTP server discussed in previous section) and send these file to Web server through serial port as shown in figure 2.

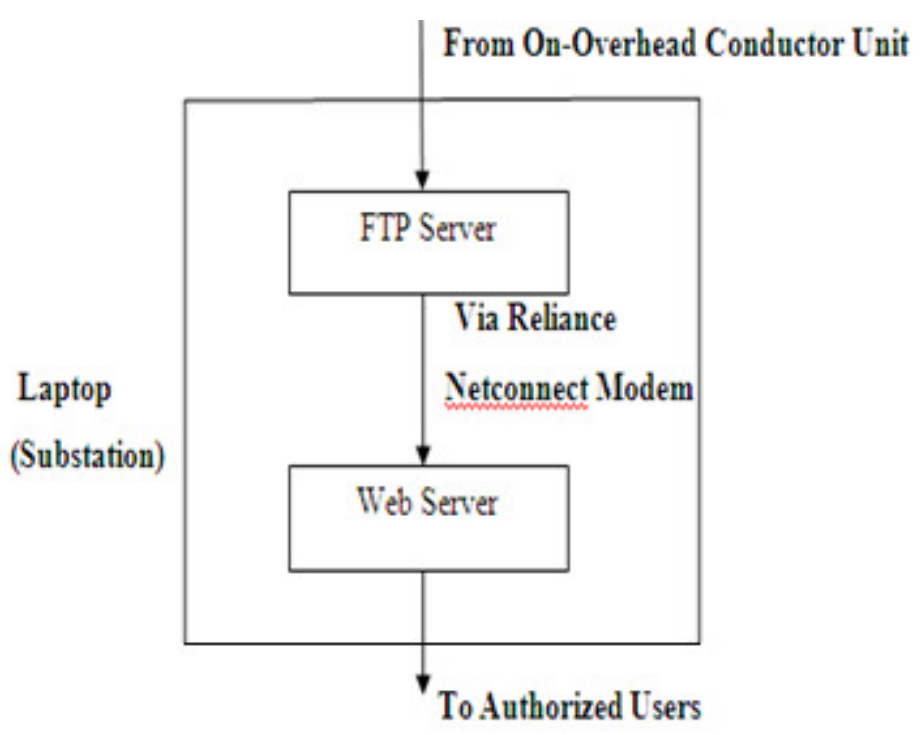

Figure2. Block Diagram of Web Server/Control Room of Substation

Since Web server will be accessible over the internet, thus access of logged file from OnOverhead Conductor Unit must be restricted to authorized users only. 


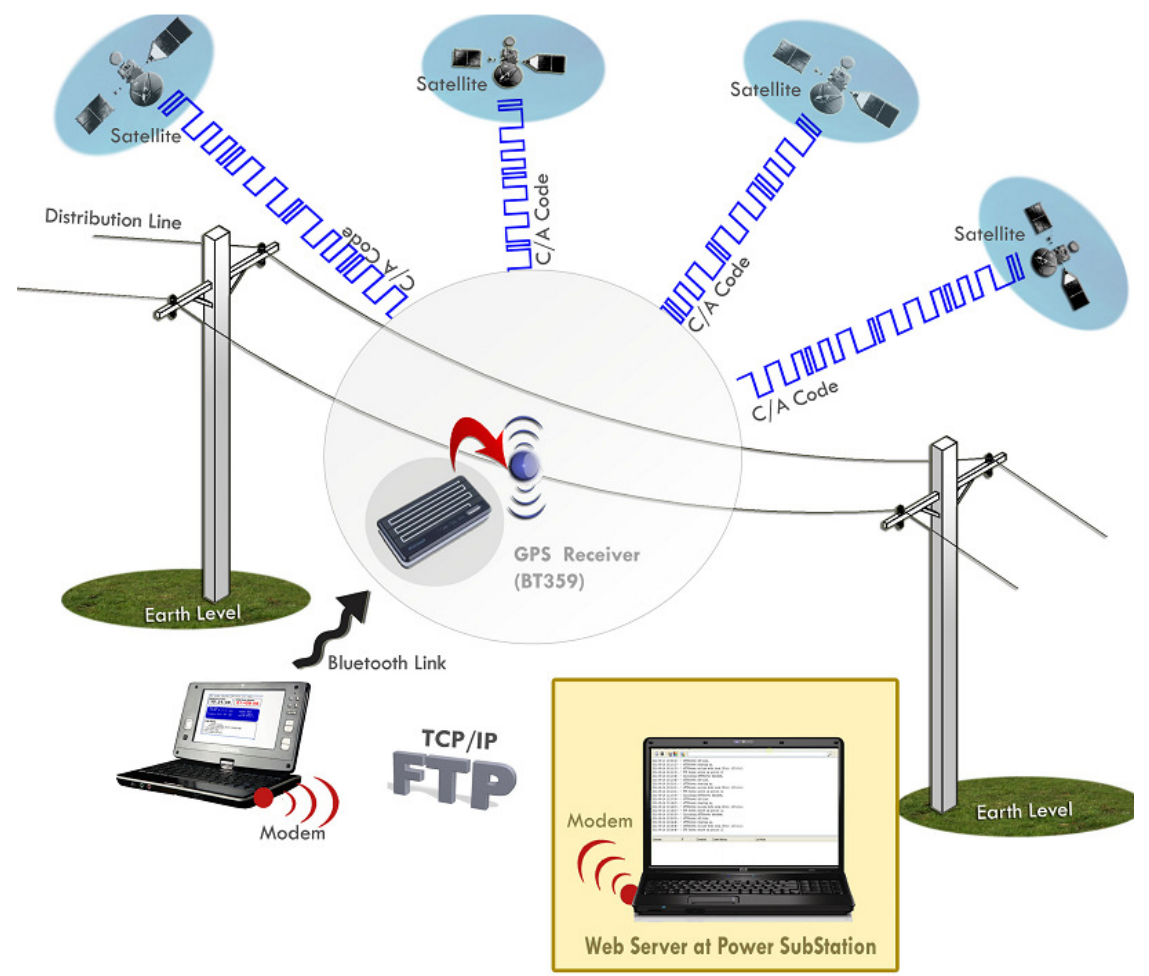

Figure3. Conceptual representation of GPS data transmission to Web Server for overhead conductor sag measurement

From Web server logged file is downloaded to laptop. But raw GPS data is not so accurate that it can be used directly for overhead conductor sag measurement. Therefore post processing of GPS data has been required to enhance the accuracy of raw GPS data. The communication between On-Overhead Conductor Unit and Remote Server/Control Room of Substation uses the TCP/IP protocol as shown in figure 3.

\section{SYSTEM TESTING}

System design needs to be verified by testing after integration of all components of the system. After integrating all components, system is tested.

\section{A. Testing On-Overhead Conductor Unit}

For testing purpose $11 \mathrm{KV}$ Public health feeder having span length of $60 \mathrm{~m}$, sector 6, Faridabad, Haryana, India is considered from where GPS data has been transmitted for overhead conductor sag measurement to remote server. After placing GPS Receiver along with polymer insulator at pole of this line and GPS receiver powered on, data is collected from GPS receiver BT359 as given in figure 4. The output provided by GPS receiver is in NMEA format. This output provided by GPS receiver is given to leaptop placed on earth below respective line via Bluetooth link. The Bluetooth device used at leaptop's COM port should be compatible with Bluetooth of GPS receiver. In the output shown in figure 4 GGA means GPS System Fix, GSA means GPS DOP and Active Satellites, GSV is GPS Satellites in View and RMC is Minimum GPS/Transit Data. 
International Journal of Computer Science, Engineering and Applications (IJCSEA) Vol.2, No.1, February 2012

The NMEA/GPS data logging software installed at leaptop extract the required information and processed it to $\log$ file as shown in figure 5 .

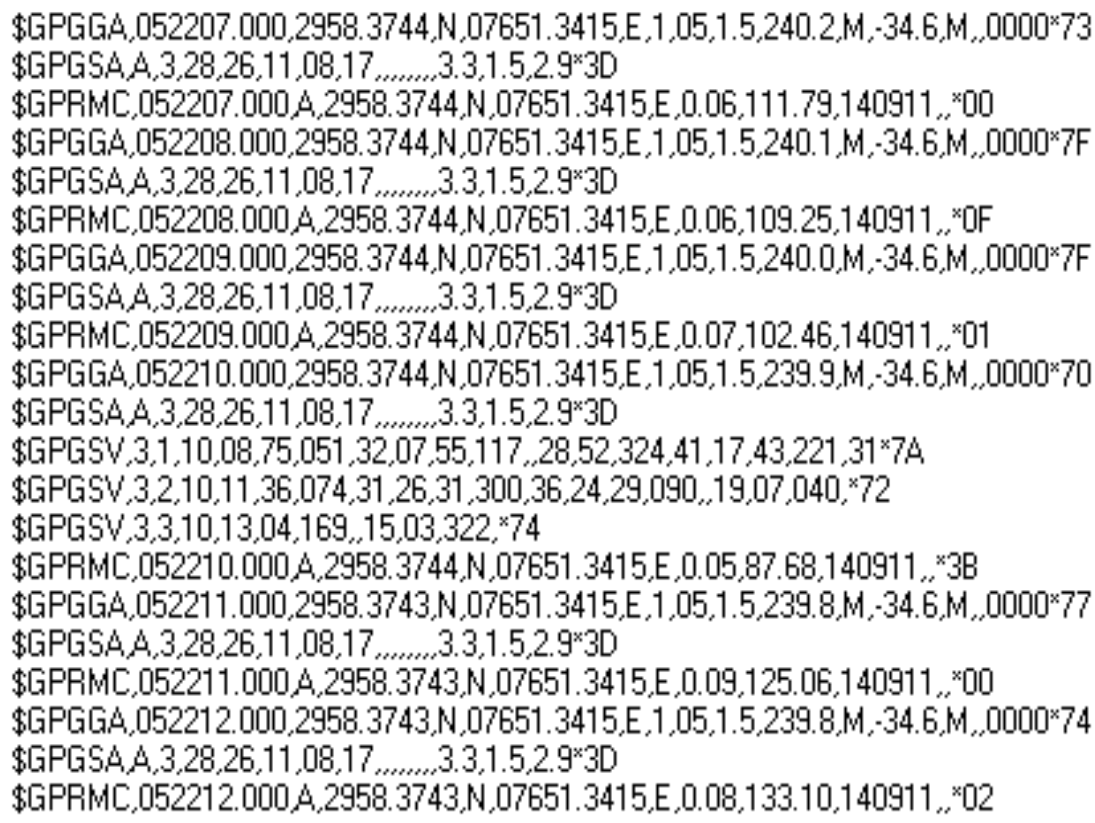

Figure4. Output of GPS Receiver

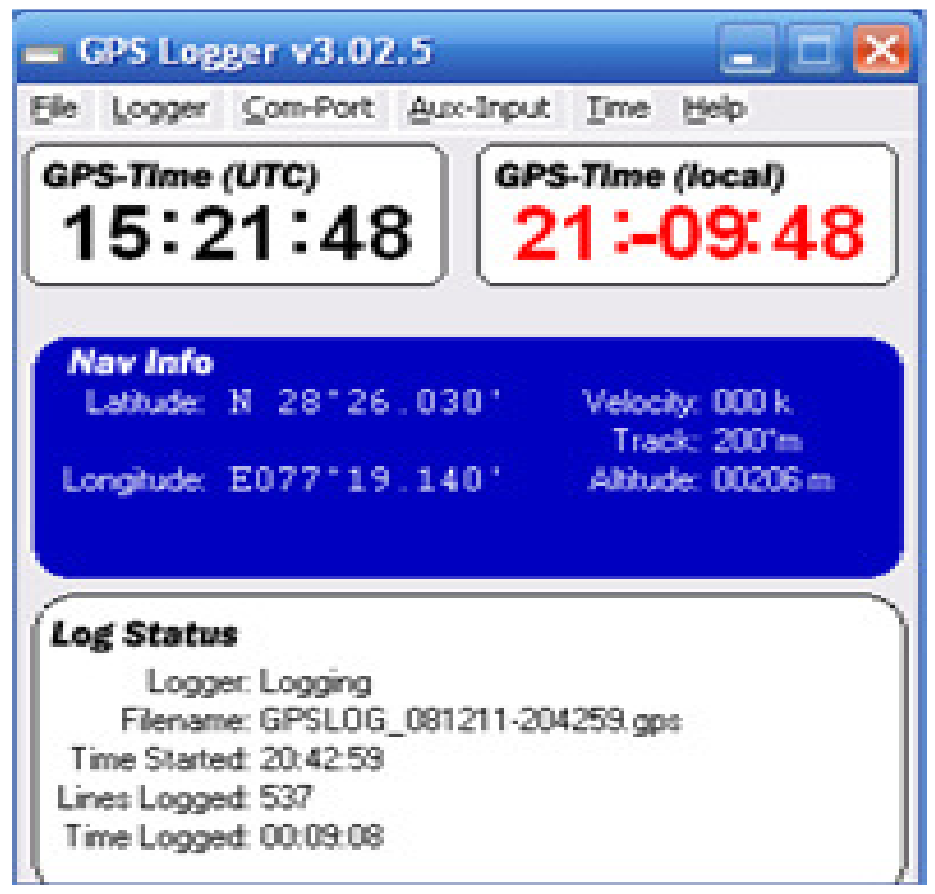

Figure 5. Logging of GPS data 
International Journal of Computer Science, Engineering and Applications (IJCSEA) Vol.2, No.1, February 2012

The figure 6 presents synchronization of logged file with FTP server in real time. As change in file is observed, file on FTP server is also changed immediately. The figure 7 shows the change of logged file.

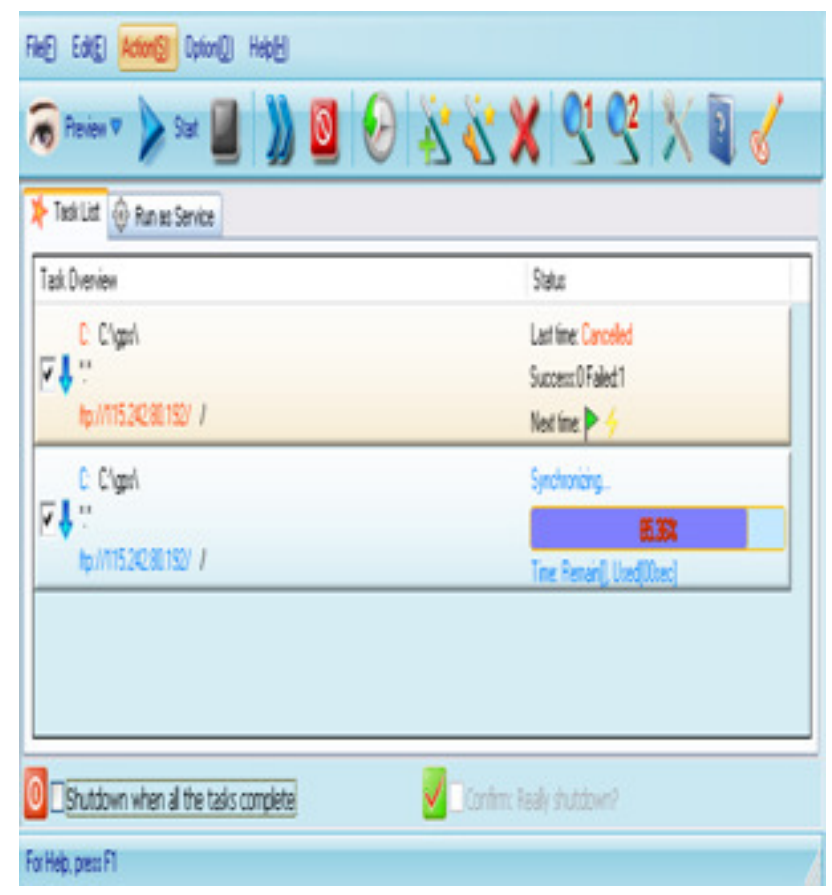

Figure6. Message Window showing GPS data Synchronization

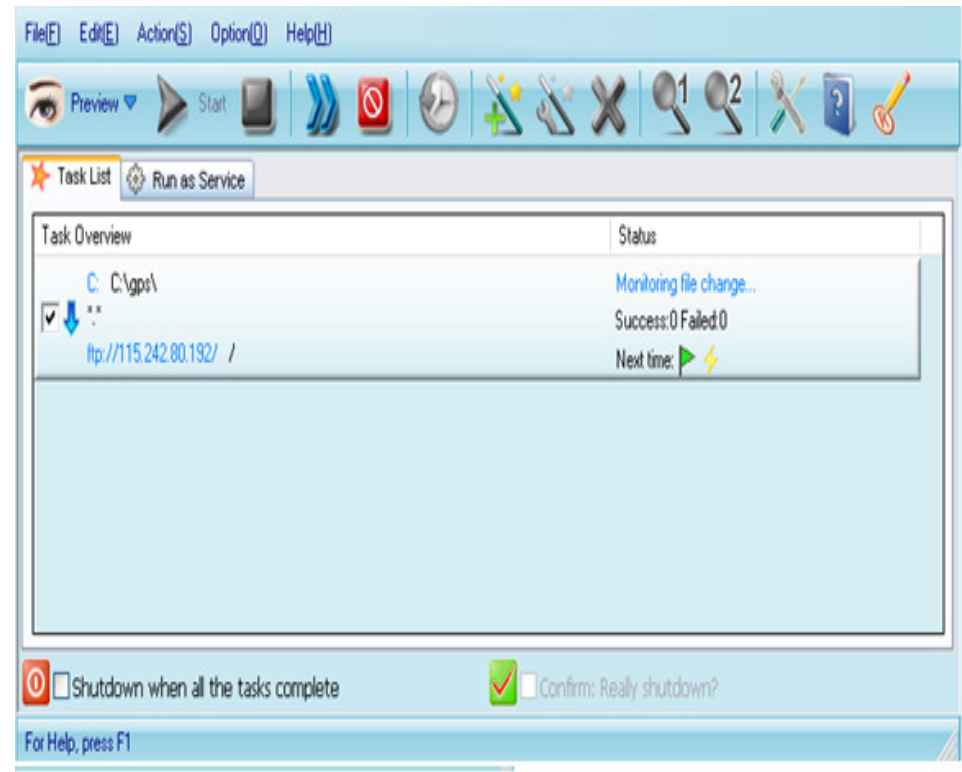

Figure7. Message Window showing change of logged file 


\section{B. Testing Remote Server/Control Room of Substation}

In order to test server, laptop is configured to act as a server. The following figure 8 presents that how logged file uploading to FTP server.

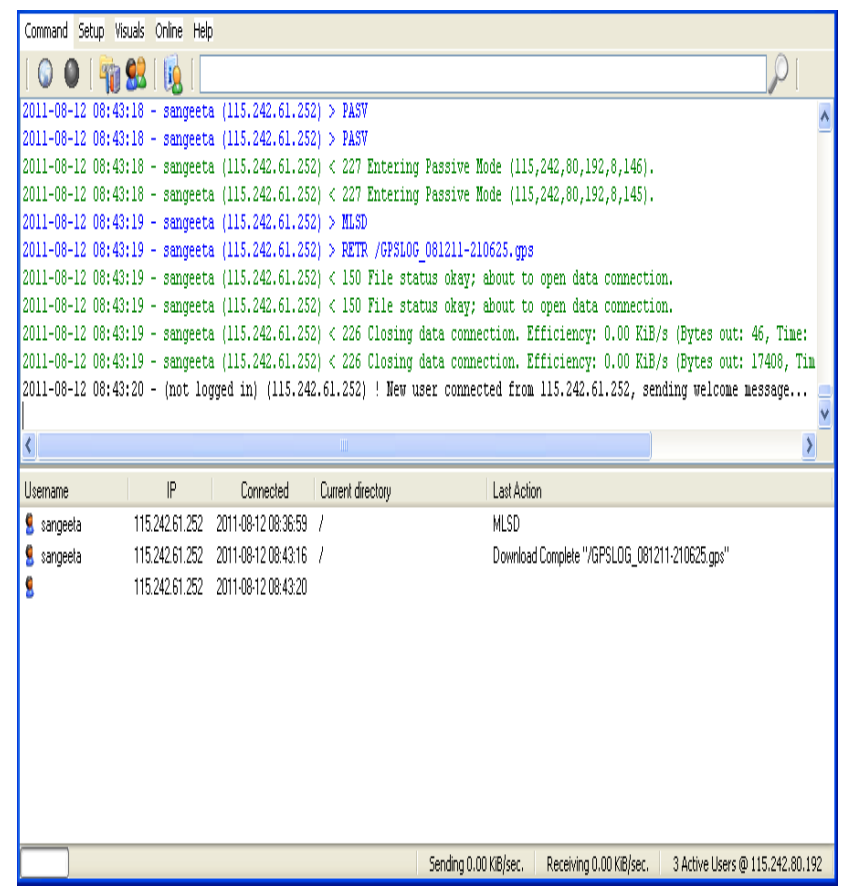

Figure8. Pointing out logged file uploading to FTP server

\section{RESULTS AND DISCUSSION}

\section{A. Observation of Raw Altitude Measurements Obtained using GPS}

The altitude of conductor has also been measured physically from the earth and the altitude of earth from mean sea level is added to it. The altitude of earth above mean sea level (Faridabad) is 198m (Pre surveyed position by Survey of India). It gives the physical measured (actual) altitude of the conductor for the estimation of error. The altitude of conductor measured physically from the earth is $8.1 \mathrm{~m}$. In this case the physical measured altitude of conductor is $206.1 \mathrm{~m}$. The altitude measurements obtained from GPS are compared with the physical altitude measurements of conductor. The physical measured altitude and raw altitude of overhead conductor measured using GPS at pole of line are presented in figure 9. 


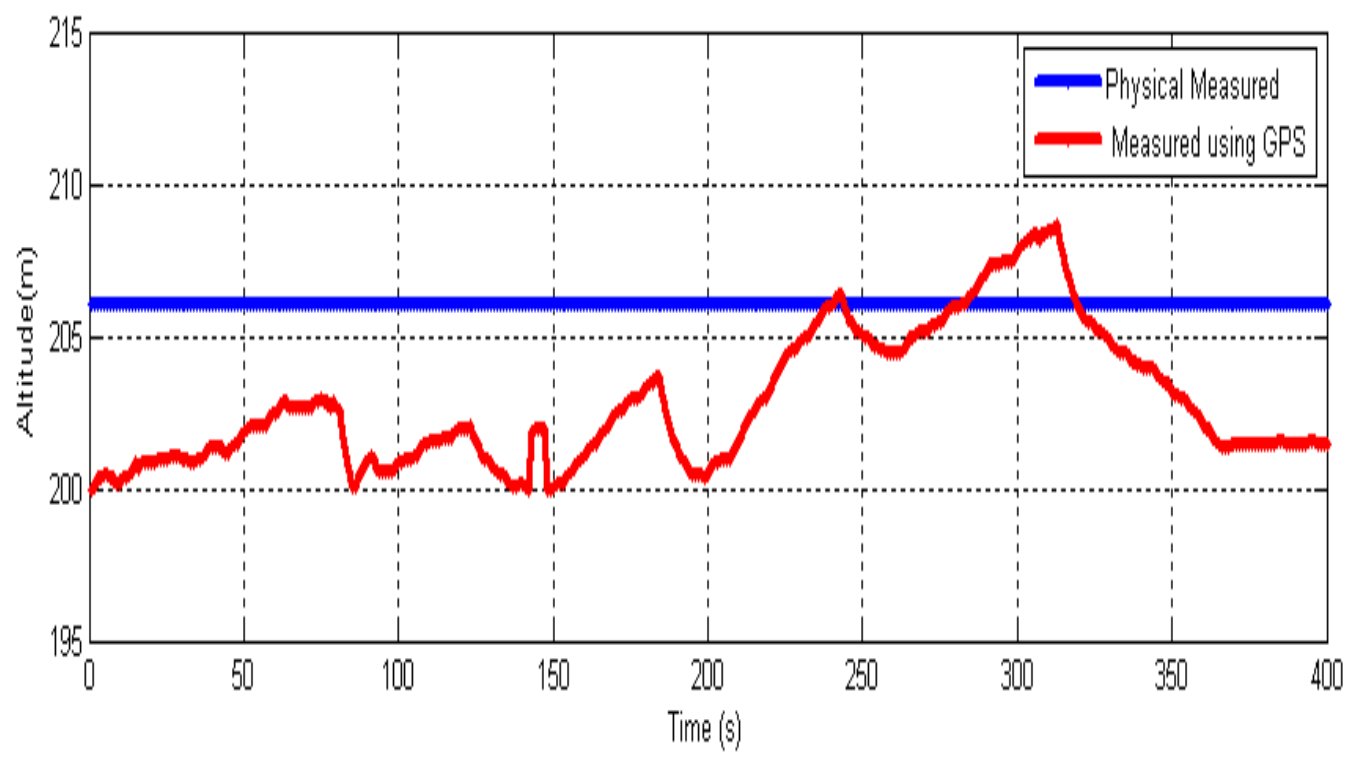

Figure9. Raw GPS altitude measurements at Pole

\section{B. Processing of Altitude measurements obtained using GPS}

In the raw altitude measurements obtained using GPS as shown in figure 9 error has been experienced with respect to its physical measured altitude of conductor. The error in altitude measurements obtained using GPS has been reduced with various signal processing techniques such as LSPE method and HWT with LSPE method [10]. As raw GPS altitude measurements has been processed using LSPE method, error in raw altitude measurements obtained using GPS has been reduced to greater extent. The figure10 depicts processed altitude measurements of conductor obtained using GPS resulting from LSPE method at pole. It has been observed that an maximum absolute error of $6.1 \mathrm{~m}$ in raw altitude measurements obtained using GPS technique has been reduced to error of $0.2 \mathrm{~m}$ after using LSPE method . It can be seen from figure 10. Also it can be observed from figure 10 that the estimated altitude measurements obtained using GPS resulting from LSPE method doesn't very much close to physical measured altitude of conductor. This could be due to further error in estimated altitude measurements obtained using GPS resulting from LSPE method. 


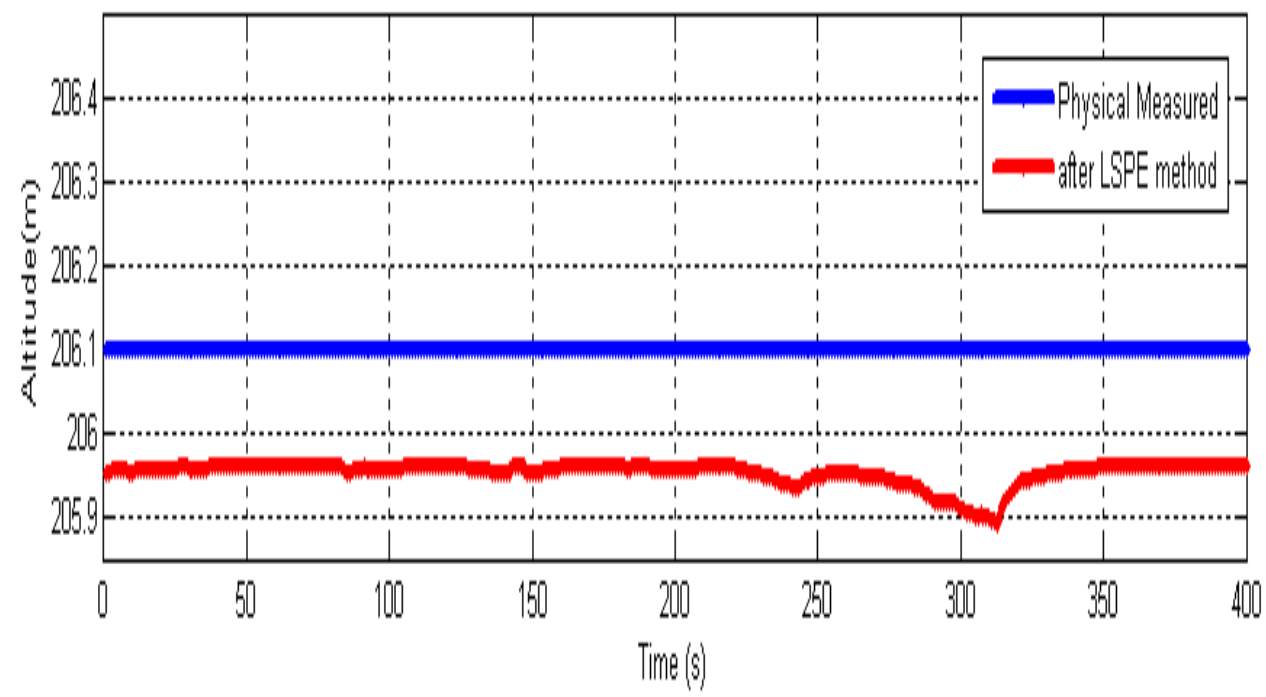

Figure 10. Effect of LSPE method on raw altitude measurements

Thus error has been further reduced using HWT with LSPE method. The results obtained after using HWT with LSPE method tend to have significantly less error when compared to output from LSPE method. Thus accuracy of observed GPS altitude measurements has improved using HWT with LSPE method as can be seen from figure 11.

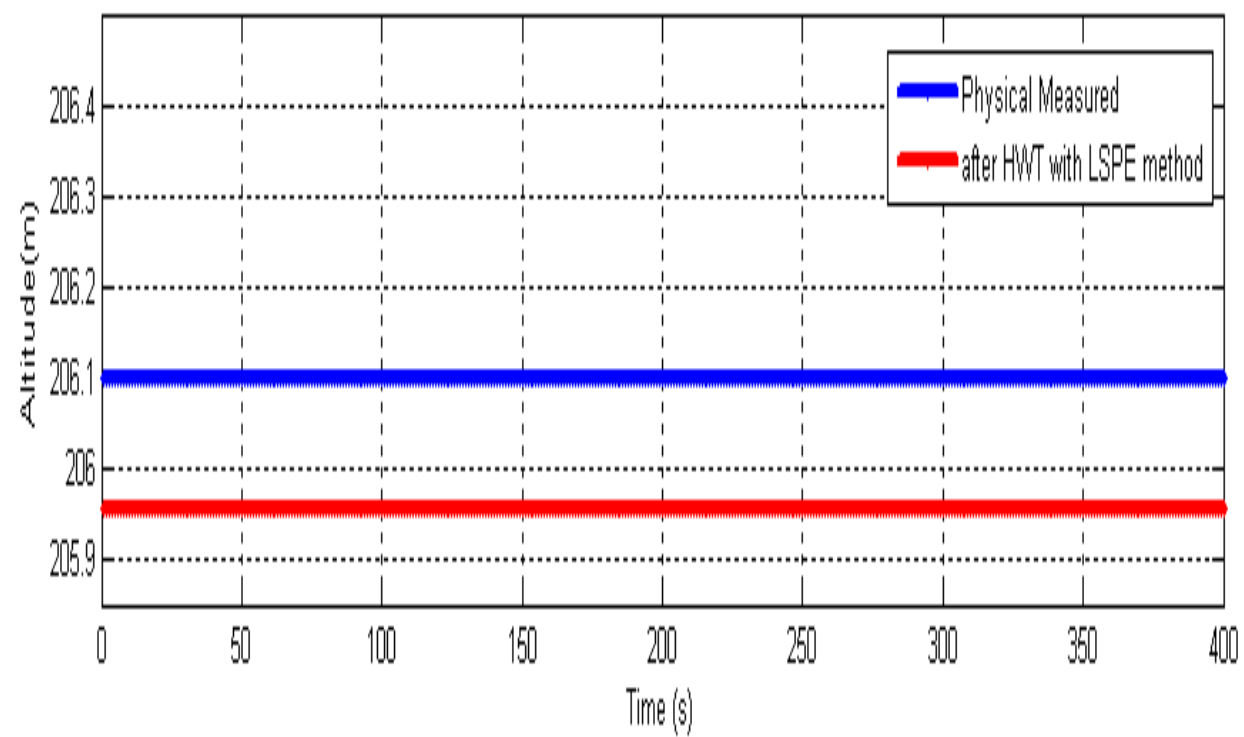

Figure 11. Effect of Haar wavelet on estimated altitude measurements resulting from LSPE method 
Thus use of Wavelet analysis to further reduce errors in estimated GPS altitude measurements resulting from LSPE method gives better accuracy of raw GPS altitude measurements taken for overhead conductor sag measurement in power line.

\section{CONCLUSION}

It can be concluded that Web based system may be used for online overhead conductor sag measurement of power transmission line using GPS at substation. It is concluded from the test results that user can access GPS data transmitted using TCP/IP for overhead conductor sag measurement at anywhere in the world using internet connection. The LSPE and HWT with LSPE method have been used to improve accuracy of GPS altitude measurements. These methods reduce error significantly. Better results are found using HWT method if it is used to process estimated GPS altitude measurements resulting from LSPE method. The DGPS receiver may also be used to get better accuracy as compared to handheld GPS receiver.

\section{ACKNOWLEDGEMENT}

We acknowledge the cooperation of Assistant Executive Engineer Hansraj, HVPNL, Faridabad, Haryana, India to carry out work.

\section{REFERENCES}

[1] Chris Mensah - Bonsu, Ubaldo Fernandez Krekeler, Gerald Thomas Heydt, Yuri Hoverson, John Schilleci, Baj. A. Agarwal, "Application of the Global Positioning System to the Measurement of Overhead Power Transmission Conductor Sag”, IEEE Transactions on Power Delivery, Vol. 17, No. 1. pp 273 - 278, January 2002.

[2] Peter H.Dana, "Global Positioning System(GPS) Time Dissemination for Real Time applications", Real Time Systems, pp 9-46, 1997.

[3] T. Pratt, C. Bostain, J. Allnutt, Satellite communication, Singapore: John Wiley \& Sons, 2005.

[4] "Introduction to the Global Positioning System for GIS and TRAVERSE", Corvallis Microtechnology, Inc. 413 S.W. Jefferson Avenue Corvallis, U.S. Publication, June, 1996.

[5] B. J. Cory, P. F. Gale, "Satellites for Power System Applications", IEE Power Engineering Journal, Vol. 7, No. 5, October 1993.

[6] Z. Q. Bo, G. Weller, F. Jiang, Q. X. Yang, "Application of GPS Based Fault Location Scheme for Distribution System”, POWERCON, Vol. 1, pp. 53-57, 1998.

[7] Muruganandham, P.R.Mukesh, "Real Time Web based Vehicle Tracking using GPS", World Academy of Science, Engineering and Technology, 2010.

[8] Alberto J., "VideoMon Mobile - Vehicle Monitoring System Based On Video, GPS, GSM/GPRS/3G AND GOOGLE MAPS", Patent PI0605735-7A2,17 November 2006.

[9] S.Kamboj, R.Dahiya, "Real Time Sag Measurement of Overhead Conductor for 11KV Power Line using Global Positioning system",IJSAT,Vol.1,No.3,May2011.

[10] S. Kamboj, R. Dahiya, "Evaluation of DTLR of Power Distribution Line from Sag Measured using GPS”, IEEE conference, ICEAS, 28-30Dec. 2011, Bhuneshwar, India. 
International Journal of Computer Science, Engineering and Applications (IJCSEA) Vol.2, No.1, February 2012

\section{Authors}

Ms. Sangeeta Kamboj received her B.Tech in Electronics and Communication from C.R.S.C.E,Murthal (Sonipat),Haryana,India and M.Tech in Electronics and Communication from J.R.V.D.U Udaypur, Rajsthan ,India. Currently, she is doing Ph.D. from National Institute of Technology, Kurukshetra (Deemed University), Haryana, India. Her research interests include Communication systems, Signal Processing and Power systems.

Dr.Ratna Dahiya received her B.Tech from GBU, Pant Nagar and M.Tech and Ph.D. degree degree in Electrical Engineering from R.E.C, Kurukshetra, Kurukshetra University, Haryana, India. Currently, she is working as faculty in Electrical Engineering Department with the National Institute of Technology,Kurukshetra (Deemed University), Haryana, India. Her research interests include SMES, Induction Machines, ASD's, power quality, motor drives and Renewable energy.
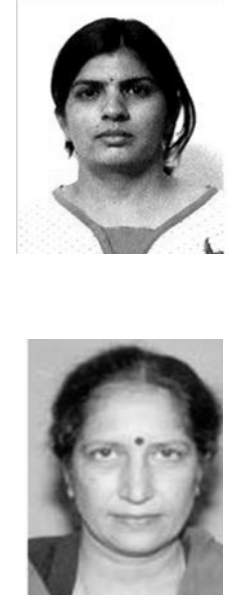